\title{
Acoustic Over-Exposure versus Human Health: A Case Study of Dangote Flour Mill, Calabar, Cross River State
}

\author{
Obiefuna, J. N¹; Kubua J. B²; Obiefuna, C. J ${ }^{3}$ \\ ${ }^{1}$ Department of Geography and Environmental Science, University of Calabar, Nigeria. \\ ${ }^{2}$ Department of Geography and Environmental Science, University of Calabar, Nigeria. \\ ${ }^{3}$ Department of Educational Foundation, Guidance and Counseling, University of Calabar, Nigeria. \\ Email: JoeObiefuna@gmail.com; Jenefak@yahoo.com; Caegocu@yahoo.com
}

\begin{abstract}
This research investigated the effects of industrial noise pollution on the health of staff members in Dangote Flour Mills, Calabar. Two hypotheses were formulated in null forms and tested at 0.05 level of significance. Noise data was collected using a sound level meter. Sound level readings were taken at different temporal periods of morning, afternoon and evening. Questionnaire was also administered to elicit relevant data on impact/perception. Data collected were analyzed using analysis of variance (ANOVA) and Pearson product moment correlation co-efficient. The finding revealed that there is a significant variation between noise level at different temporal periods in Dangote flour mills. Besides, there is also a significant effect of high noise level on the health status of members of staff. Based on these findings, appropriate recommendations were made which include that the federal and state governments should enforce policies against certain level of noise pollution in industries in the state. The management of the company should ensure that the WHO regulations on industrial noise pollution are implemented and adhered to within the working environment. Workers and/or staff of the company should wear ear protective devices to reduce the effect of the noise on them. Finally, it was also recommended that the management of the company should endeavour to get machines with the least noise level when making purchases of equipments for processing in order to reduce the effect of noise on the workers.
\end{abstract}

Keywords: Acoustic over-exposure, noise level, industrial noise pollution, human Health.

\section{Introduction}

Noise pollution is the disturbing or excessive acoustic emmission that may harm the activities or balance of human and animal life. Sound becomes unwanted when it either interferes with normal activities such as sleeping, conversation, or disrupts or diminishes one's quality of life as well as health [1]

Environmental noise, particularly generated due to socio-economic activities in urban areas, has a significant impact on human well-being[2]. Ensuring that noise does not reduce the quality of life needs a precise measurement of its levels using a scientific method. Poor urban planning may give rise to high noise level since industrial and residential buildings constructed side-by-side can result to noise pollution in the residential area. Poor urban planning results to a rise in noise pollution and measurement of these noise levels have become essential in order that it may be compared with medically safe standard for urban residents[3].

Elevated industrial noise pollution can cause hearing impairment, hypertension, heart disease, annoyance, and sleep disturbance. Changes in the immune system and birth defects have been attributed to noise exposure[4]. Although some presbycusis (age-related hearing loss) may occur naturally with age, in many developed nations the cumulative impact of industrial noise pollution is sufficient to impair the hearing of a large fraction of the population over the course of a lifetime[5]. Noise exposure has also been known to induce hypertension, vasoconstriction, and other cardiovascular adverse effects.

Beyond these impact, industrial noise pollution can create stress, increases workplace accident rates, and stimulates aggression and other anti-social behaviors[4].

In the workplace, industrial noise pollution is generally a problem once the noise level is greater than $55 \mathrm{~dB}(\mathrm{~A})$. Studies show that approximately $35 \%$ to $40 \%$ of office workers find noise levels from 55 to 60 
$\mathrm{dB}(\mathrm{A})$ extremely irritating [5]. The noise standard in Germany for mentally stressful tasks is set at 55 $\mathrm{dB}(\mathrm{A})$, however, if the noise source is continuous, the threshold level for tolerability among office workers is lower than $55 \mathrm{~dB}(\mathrm{~A})[5]$.

One important impact of industrial noise pollution is to make a person's speech less easy to hear[6]. The human brain compensates for background noise during speech production in a process called the Lombard effect in which speech becomes louder with more distinct syllables. However, this cannot fully remove the problems of communication intelligibility made in the presence of noise.

Industrial noise pollution causes trauma to cochlear structure in the inner ear, which gives rise to irreversible hearing loss. A very loud sound in a particular frequency range can damage the cochlea's hair cells that respond to that range, thereby reducing the ear's ability to hear those frequencies in the future, however, loud noise in any frequency range has deleterious effects across the entire range of human hearing. The outer ear (visible portion of the human ear) combined with the middle ear amplifies sound levels by a factor of 20 when sound reaches the inner ear[7].

Industrial Noise pollution has been found to be associated with important cardiovascular health problems. Fairly typical industrial noise pollutions are sufficient to constrict arterial blood flow and lead to elevated blood pressure; in this case, it appears that a certain fraction of the population is more susceptible to vasoconstriction that is, those living or working within Dangote flour mills, Calabar. This may be because annoyance from the sound causes elevated adrenaline levels triggering a narrowing of the blood vessels (vasoconstriction), or independently through medical stress reactions. Other effects of high noise levels are increased frequency of headaches, fatigue, stomach ulcers, and vertigo [8].

When young children are regularly exposed to industrial noise pollution that interfere with speech, they may develop speech or reading difficulties, because auditory processing functions are compromised. Children continue to develop their speech perception abilities until they reach their teens. Evidence has shown that when children learn in noisier classrooms, they have a more difficult time understanding speech than those who learn in quieter settings.

The U.S. Environmental Protection Agency authored a pamphlet in 2008 that suggested a correlation between low-birthweight (using the World Health Organization definition of less than 2,500 g ( $5.5 \mathrm{lb}$ ) and high sound levels, and also high rates of birth defects in places where expectant mothers are exposed to elevated industrial noise pollution, such as typical industrial noise polluted environment. Specific birth abnormalities included harelip, cleft palate, and defects in the spine.

Noise levels are measured in decibels (db) using a sound pressure level meter called the decibel meter. People exposed to 95-100 decibels of sound for extended periods may suffer from physical and emotional discomfort and deafness. Whispering produces about 20decibels of sound while natural conversation is around 50 decibels $(\mathrm{db})$. Sound pressure becomes painful at $120 \mathrm{dbs}$ and can kill at $180 \mathrm{dbs}[7]$. The following are the major impacts of industrial noise pollution on human health: hearing loss, cardiovascular effects, hypertension, cognitive development, child's physical development or loss of weight in unborn children, vasoconstriction, and stress. This research work was therefore aimed at investigating the effects of industrial noise pollution on human health using Dangote flour mills, Calabar, Cross River state as a case study.

\section{$1.1 \quad$ The Issue}

Exposure to noise constitutes a health risk. There is sufficient scientific evidence that industrial noise pollution can induce hearing impairment, hypertension and ischemic heart disease, sleep disturbance, decreased school performance, annoyance and cardiovascular disorders. For other effects such as changes in the immune system and birth defects, the evidence is unlimited. Most public health impacts of industrial noise pollution were already identified in the 1980s and noise abatement is less of a scientific but primarily a policy problem. Several people have carried out studies on noise in industries in Calabar but none of these people carried out studies on the variation in noise level at different temporal periods which this research work considered.

A visit to Dangote flour mills, Calabar with a sound level meter reveals that Industrial noise pollution is beyond the normal hearing threshold. This problem can be noticed both in industrialised nation and in developing world regions as put forward [9]. This therefore implies that now and in the next century, noise exposure will still be a major health problem to the people working in and living around this area if nothing is done about the situation. Workers have been identified to be working in an unsafe 
environment and most of them do not wear any form of protective device against noise. Besides, workers seem to be engaged in an environment where the exact noise level is not known. This situation is a risky one.

Industrial noise pollution takes place when there is either excessive amount of noise or an unpleasant sound that causes temporary disruption in the natural balance. This definition is usually applicable to sounds or noises that are unnatural in either their volume or their production. The environment of Dangote flour mills, Calabar is such that it has become difficult to escape noise pollution.

The problems under review which militate against workers and people living around the flour mills are the extent to which industrial noise polution causes deafness and hard of hearing in people and the extent to which exposure to industrial noise pollution affects the health of members of staff.

\subsection{Aim and Objectives}

The major aim of this study is to investigate the effects of industrial noise pollution on human health using a case study of Dangote Flour mills, Calabar.

The objectives includes;

1. To generate sound level data for the study area.

2. To investigate the temporal changes in noise levels in the study area.

3. To examine the various effects of industrial noise on the members of staff.

4. To make recommendations towards reduction of industrial noise exposure and the improvement of working conditions so as to enhance human health.

\subsection{Research Hypotheses}

The following research hypotheses were formulated and tested.

1. There is no significant variation in noise levels acquired at different temporal periods in Dangote flour mills.

2. There is no significant relationship between high noise level and the health status of members of staff.

\subsection{The Study Area}

The research location is Dangote flour mills in the industriall zone /Export Processing Zone, located in Calabar Municipal Local Government Area. Calabar Municipal lies between latitude $0415 \mathrm{~N}$ and longitude $0825 \mathrm{E}$. It is one of the eighteen (18) Local Governments that make up the present Cross River State. Geographically, Calabar Municipal Local Government Area is bounded in the North by Odukpani Local Government Area, in the south by Calabar South Local Government Area, in the east by the great Kwa river and in the west by Akpabuyo Local Government Area respectively.

\section{Method of Study}

\subsection{Instruments for Data Collection}

The major instrument that was used for data collection was questionnaire and mini digital handheld sound level meter (PYLE PSPL01). It is a compact and portable digital sound level meter with a measuring range of 30 to $130 \mathrm{~dB}$. The ranges are Low (0 to 100dB) and High (60 to $130 \mathrm{~dB}$ ), with an accuracy of $\pm 1.5 \mathrm{~dB}$. The sound level meter meets the International Electrotechnical Commission (IEC) 651 Type II standard, and includes frequency weighting of $\mathrm{A}$ and $\mathrm{C}$ and fast and slow time weighting. The A-weighting was used because of its recommendation for environmental and industrial studies (Peterson and Gross, 1974).

The questionnaire was made up of three sections, section A, B and C. Section A consisted of personal data of the respondents, section $\mathrm{B}$ dealt with information on noise and equipment that generate noise while section $\mathrm{C}$ dealt on the impact of the noise polution as well as the way forward. 


\subsection{Data Collection}

The questionnaire was distributed by the researcher to the respondents in their various sections of the factory and the questionnaires were collected immediately after the respondents have filled them out to avoid loss of questionnaire. Sixty (60) questionnaires were administered by the researcher and all were returned. A comprehensive survey of the area was also done by taking and monitoring noise level readings. Noise data were taken from the point sources at a distance of one meter. The noise level reading was taken at differnt times in the mornings, afternoons and evenings of Monday, Tuesday, Wednesday, Thursday, Friday and Saturday.

\subsection{Data Analysis}

Data collected were analyzed using Pearson's product moment correlation coefficient analysis (PPMCCA) and analysis of variance (ANOVA).

The formula for Pearson's product moment correlation coefficient is given as:

$$
R x y=\frac{\mathrm{NXY}-\mathrm{XY}}{\sqrt{\left.\left.\mathrm{NX}^{2}-\mathrm{X}\right)^{2} \mathrm{NY}^{2}-\mathrm{Y}\right)^{2}}}
$$

While the mathematical definition of Analysis of Variance (ANOVA) is given as:

$$
\begin{aligned}
& \sum_{i j}^{k} \sum_{i j}^{n}\left(\mathrm{X}_{i j}-\bar{X}\right)^{2}=(x+a)^{n}=\sum_{i j} n i\left(X_{1}-\bar{X}\right)^{2}+\sum_{i j}\left(X_{i j}\right) \\
& T S S=B S S+W S S
\end{aligned}
$$

where:

TSS $=$ Total Sum of Squares (total mean squares of all locations)

BSS = Between Group Sum of Squares (the sum of square of observations made)

WSS $=$ Within Group Sum of Squares (the sum of square of observations made at different time periods)

$\mathrm{K}=$ Number of Samples (6 sampled points)

$\mathrm{N}=$ Number of Observations (number of all observations in all locations)

$X_{\mathrm{ij}}=$ Value of the ith and jth observation

$\bar{X}=$ Mean

$X_{i}=$ Mean for the ith sample

$\sum \sum=$ Summation of all items in the matrix i.e. all " $\mathrm{k}$ " or " $\mathrm{n}$ " (noise level across the days of the week over different time periods)

The decision rule that is used to determine whether or not to accept the null hypothesis states that the null hypothesis is rejected when the calculated r-value is greater than the critical r-value.

\section{$3 \quad$ Results and Discussion}

Table 1. Data of respondents from questionnaire distributed

\begin{tabular}{l|l|l}
\hline Qustion & NO. of Respondent & \% of Respondent \\
\hline 1 & 55 & 91.6 \\
\hline 2 & 58 & 96.6 \\
\hline 3 & 59 & 98.3 \\
\hline 4 & 60 & 100 \\
\hline 5 & 58 & 96.3 \\
\hline 6 & 57 & 95.0 \\
\hline 7 & 60 & 100 \\
\hline 8 & 54 & 90.0 \\
\hline
\end{tabular}




\begin{tabular}{l|l|l}
\hline 9 & 59 & 98.3 \\
\hline 10 & 60 & 100 \\
\hline \multicolumn{2}{c}{ Source: Analysis by author, 2014.}
\end{tabular}

Table 2. Morning noise level in the study area

\begin{tabular}{l|l}
\hline DAYS & $\mathbf{X}_{1}$ \\
\hline MONDAY & 95.0 \\
\hline TUESDAY & 95.5 \\
\hline WEDNESDAY & 79.6 \\
\hline THURSDAY & 86.9 \\
\hline FRIDAY & 74.8 \\
\hline SATURDAY & 50.8 \\
\hline
\end{tabular}

Source: Analysis by author, 2014.

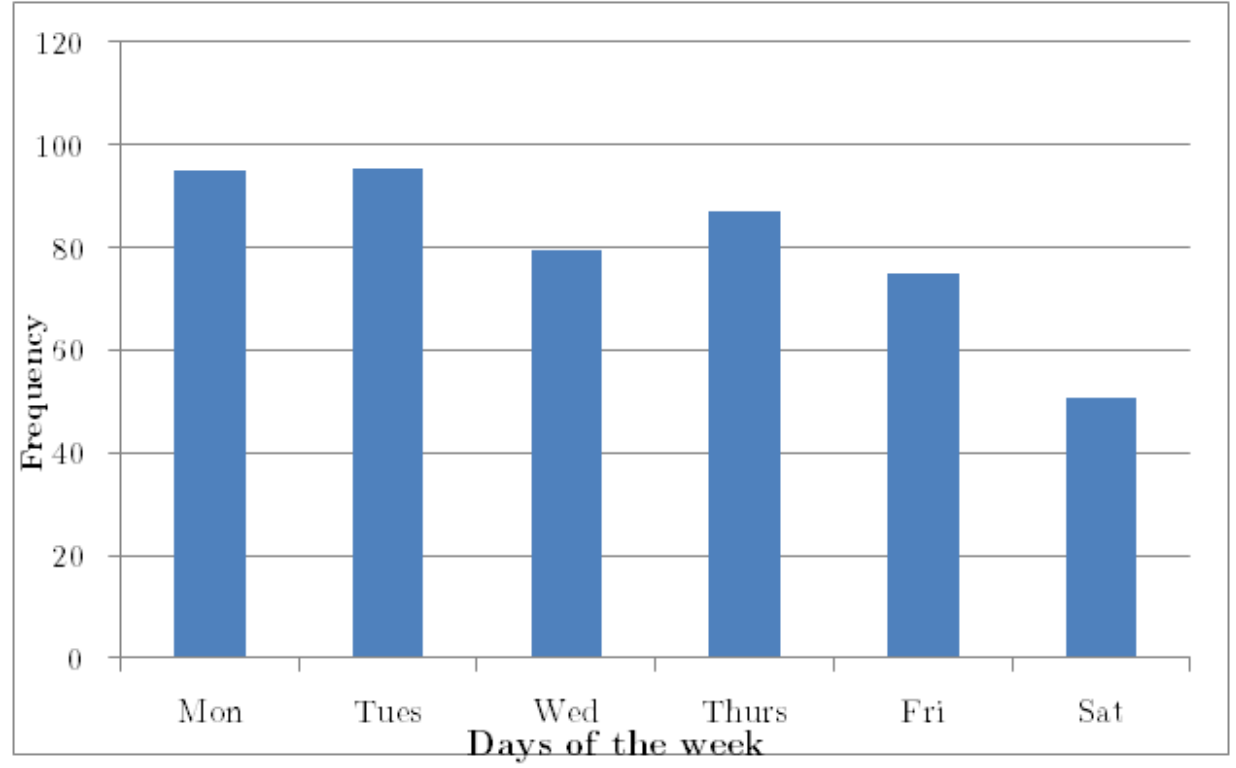

Figure 1. Morning noise level in the study area (Source: Author's field work, 2014.)

Table 3. Afternoon noise level in the study area.

\begin{tabular}{l|l}
\hline DAYS & $\mathbf{X}_{2}$ \\
\hline MONDAY & 99.6 \\
\hline TUESDAY & 97.8 \\
\hline WEDNESDAY & 89.0 \\
\hline THURSDAY & 99.9 \\
\hline FRIDAY & 82.1 \\
\hline SATURDAY & 59.5 \\
\hline
\end{tabular}

Source: Analysis by author, 2014. 


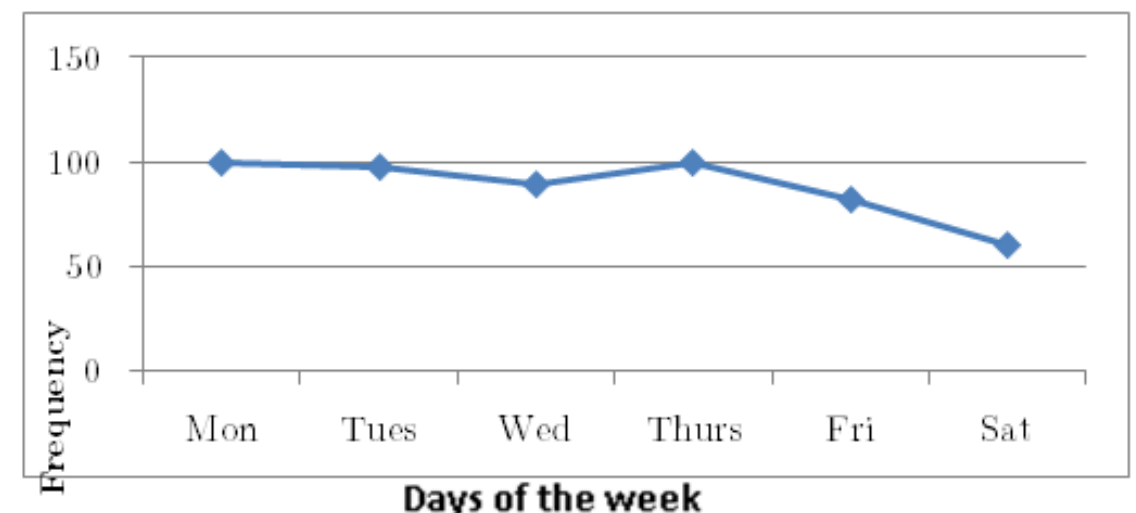

Figure 2. Afternoon noise level in study area (Source: Author's field work, 2014.)

Table 4. Evening noise level in the study area

\begin{tabular}{l|l}
\hline DAYS & $\mathbf{X}_{3}$ \\
\hline MONDAY & 81.7 \\
\hline TUESDAY & 93.2 \\
\hline WEDNESDAY & 73.5 \\
\hline THURSDAY & 84.4 \\
\hline FRIDAY & 70.7 \\
\hline SATURDAY & 25.0 \\
\hline
\end{tabular}

Source: Analysis by author, 2014

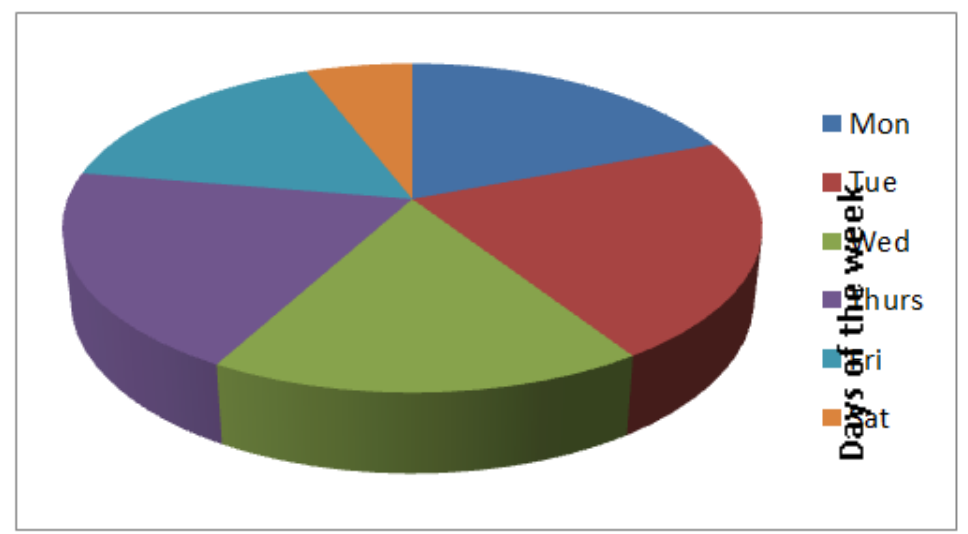

Figure 3. Evening noise level in study area (Source: Author's fieldwork, 2014)

\subsection{Hypothesis One}

Table 5. Noise generated from a point source in dangote flour mills, calabar

\begin{tabular}{|c|c|c|c|c|c|c|c|c|c|c|c|}
\hline & & \multicolumn{3}{|c|}{$\begin{array}{l}\text { Morning Noise Level } \\
\text { (dB)A }\end{array}$} & \multicolumn{3}{|c|}{$\begin{array}{l}\text { Afternoon Noise Level } \\
(\mathrm{dB}) \mathrm{A}\end{array}$} & \multicolumn{3}{|c|}{$\begin{array}{l}\text { Evening Noise Level } \\
\text { (dB)A }\end{array}$} & \\
\hline & & \multicolumn{3}{|c|}{ 9:00AM } & \multicolumn{3}{|c|}{ 12:00PM } & \multicolumn{3}{|c|}{ 4:00PM } & \\
\hline $\mathrm{S} / \mathrm{N}$ & Days & Max & Min & $\mathrm{X}$ & Max & Min & $\mathrm{X}$ & Max & Min & $\mathrm{X}$ & NS \\
\hline 1. & $\mathrm{MON}$ & 99.7 & 90.3 & 95.0 & 101.4 & 97.8 & 99.6 & 83.6 & 79.8 & 81.7 & $*$ \\
\hline 2. & TUE & 99.2 & 91.8 & 95.5 & 100.6 & 94.9 & 97.8 & 96.9 & 89.5 & 93.2 & $* *$ \\
\hline
\end{tabular}




\begin{tabular}{l|l|l|l|l|l|l|l|l|l|l|l}
\hline 3. & WED & 82.7 & 76.5 & 79.6 & 92.4 & 85.6 & 89.0 & 76.9 & 70.1 & 73.5 & $\# \#$ \\
\hline 4. & THUR & 91.4 & 82.3 & 86.9 & 102.8 & 96.9 & 99.9 & 88.7 & 80.1 & 84.4 & $* *$ \\
\hline 5. & FRI & 79.4 & 70.1 & 74.8 & 84.6 & 79.6 & 82.1 & 72.6 & 68.8 & 70.7 & $\# \#$ \\
\hline 6. & SAT & 58.9 & 42.6 & 50.8 & 60.1 & 58.9 & 59.5 & 30.0 & 20.0 & 25.0 & $* * *$ \\
\hline
\end{tabular}

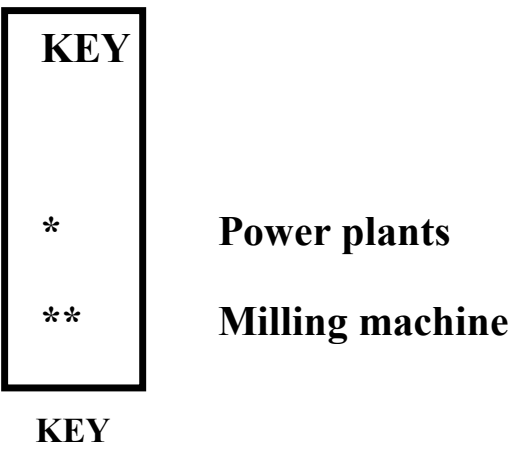

Table 6. Square of the noise reading

\begin{tabular}{l|l|l|l|l|l|l}
\hline DAYS & $\mathrm{X}_{1}$ & $\mathrm{X}_{\mathbf{1}}{ }^{2}$ & $\mathrm{X}_{2}$ & $\mathrm{X}_{\mathbf{2}}{ }^{2}$ & $\mathrm{X}_{3}$ & $\mathrm{X}_{\mathbf{3}}{ }^{2}$ \\
\hline MON & 95.0 & 9025.00 & 99.6 & 9920.16 & 81.7 & 6674.89 \\
\hline TUE & 95.5 & 9120.25 & 97.8 & 9564.84 & 93.2 & 8686.24 \\
\hline WED & 79.6 & 6336.16 & 89.0 & 7921.00 & 73.5 & 5402.25 \\
\hline THURS & 86.9 & 7551.61 & 99.9 & 9980.01 & 84.4 & 7123.36 \\
\hline FRI & 74.8 & 5595.61 & 82.1 & 6740.41 & 70.7 & 4998.49 \\
\hline SAT & 50.8 & 2580.64 & 59.5 & 3540.25 & 25.0 & 625.00 \\
\hline TOTAL & $\mathbf{4 8 2 . 6}$ & $\mathbf{4 0 2 0 8 . 7}$ & $\mathbf{5 2 7 . 9}$ & $\mathbf{4 7 6 6 6 . 6 7}$ & $\mathbf{4 2 8 . 5}$ & $\mathbf{3 3 5 1 0 . 2 3}$ \\
\hline \multicolumn{7}{c}{ Source: Analysis by Author, 2014 }
\end{tabular}

From the readings obtained from the sound level meter, it was observed that the least minimum sound recorded in the morning hours in a week is 42.6 while the maximum is 99.7 . For the afternoon, the minimum sound level is 58.9 while the maximum is 102.8 , for the evening, the minimum sound level is 20.0 while the maximum is 96.9 . On the whole, the average noise level recorded is 70 .

$\mathrm{n}_{1=6}, \quad \mathrm{n}_{2=6,} \quad \mathrm{n}_{3=6}$
recall, $\mathrm{N}=\frac{\sum X}{n}$

Reading $\quad \bar{X}=\frac{482.6}{6}=80.43$

(Morning)

Reading $2 \quad \bar{X}=\frac{528.9}{6}=87.98$

(Aternoon)

Reading $1 \quad \bar{X}=\frac{482.5}{6}=71.42 .43$

(Evening)

Recall, $\sum \sum X^{2}=\sum X_{1}^{2}+\sum X_{2}^{2}$ ? $+\sum X_{3}^{2}$

$$
\begin{aligned}
& =40208.7+47666.6+33510.23 \\
& =121385.6
\end{aligned}
$$




$$
\begin{aligned}
\sum X & =\sum X_{1}+\sum X_{2}+\sum X_{3} \\
& =482.6+527.9+428.5 \\
& =1439 \\
\frac{G^{2}}{N} & =\frac{1439^{2}}{18}=\frac{2070721}{18}=115040.0 \\
\mathrm{SS}_{\mathrm{T}} & =121385.6-115040.0 \\
& =6345.54 \\
\mathrm{SS}_{\mathrm{B}} & =\frac{\left(\sum X_{1}\right)^{2}}{n_{1}}+\frac{\left(\sum X_{2}\right)^{2}}{n_{2}}+\frac{\left(\sum X_{3}\right)^{2}}{n_{3}}-\frac{\left(\sum X\right)^{2}}{N} \\
\mathrm{SS}_{\mathrm{B}} & =\frac{482.6^{2}}{6} \cdot+\frac{527.9^{2}}{6} \cdot+\frac{482.5^{2}}{6} .-115040 \\
\mathrm{SS}_{\mathrm{B}} & =777.32 \\
\mathrm{SS}_{\mathrm{W}} & =\sum \sum X^{2}-\sum \frac{T^{2}}{n} . \\
& =121385.6-115817.32 \\
& =5568.28
\end{aligned}
$$

Degree of freedom

$=\mathrm{N}-1$

$=18-1=17$

$\mathrm{df}_{\mathrm{B}}=\mathrm{K}-1$, where $\mathrm{K}=$ no. Of groups

$=3-1=2$

$\mathrm{df}_{\mathrm{W}}=\mathrm{N}-\mathrm{K}$, where $\mathrm{N}$ is the total no. Of scores

$$
=18-3=15
$$

Mean score (MS)

$\mathrm{MS}_{\mathrm{B}}=\frac{S S_{B}}{d f_{B}} .=\frac{777.32}{2} .=388.66$

$\mathrm{MS}_{\mathrm{w}}=\frac{S S_{W}}{d f_{W}} .=\frac{5568.28}{15} .=371.2$

F-ratio $=\frac{M S_{B}}{M S_{W}} \cdot=\frac{388.66}{371.2} .=1.05$

Calculated F-value $=1.05$

Critical F-value $=3.68$

Table 7. Summary of one way ANOVA of the variation between noise level at different temporal periods in Dangote flour mills, Calabar.

\begin{tabular}{lllll}
\hline Sources of variation & SSdf & & MSF & 1.05 \\
\hline Between Group & 777.32 & 2 & 388.66 & \\
Within Groups & 5568.28 & 15 & 371.20 & \\
Total & $\mathbf{6 3 4 5 . 6}$ & $\mathbf{1 7}$ & & \\
\hline
\end{tabular}

Significance at $0.05, \mathrm{df}=2 \& 15$

Source: Analysis by the Author, 2014

From table 7 above, the calculated F-value of 1.05 is lower than the tabulated F-value of 3.68 with a degree of freedom of 2 and 15 at 0.05 level of significance. This implies that the null hypothesis is 
retained which states that: that there is no significant variation between noise level at different temporal periods in Dangote flour mills.

\subsection{Hypothesis Two}

The hypothesis states that there is no significant relationship between high noise level and the health status of memebers of staff. The analysis of this hypothesis is presented in table 8 .

From the table above it can be seen that the percentage of people who attempted to answer the questions is high ranging from $91.6 \%$ to $100 \%$ with an average of $95.8 \%$

Table 8. Showing the calculation of hypothesis 2 using (PPMCCA)

\begin{tabular}{l|l|l|l|l|l}
\hline ITEM & $\mathbf{X}$ & $\mathbf{Y}$ & $\mathbf{X}^{2}$ & $\mathbf{Y}^{\mathbf{2}}$ & $\mathrm{XY}$ \\
\hline 1 & 40 & 35 & 1600 & 1225 & 1400 \\
\hline 2 & 30 & 30 & 900 & 900 & 900 \\
\hline 3 & 50 & 40 & 2500 & 1600 & 2000 \\
\hline 4 & 25 & 25 & 625 & 625 & 625 \\
\hline 5 & 55 & 50 & 3025 & 2500 & 2750 \\
\hline 6 & 50 & 45 & 2500 & 2025 & 2250 \\
\hline 7 & 35 & 35 & 1225 & 1225 & 1225 \\
\hline 8 & 60 & 55 & 3600 & 3025 & 3300 \\
\hline 9 & 45 & 40 & 2025 & 1600 & 1800 \\
\hline 10 & 45 & 50 & 2025 & 2500 & 2250 \\
\hline & $\mathbf{4 3 5}$ & $\mathbf{4 0 5}$ & $\mathbf{2 0 0 2 5}$ & $\mathbf{1 7 2 2 5}$ & $\mathbf{5 0 0}$ \\
\hline
\end{tabular}

Recall,

$$
\begin{aligned}
& \text { Rxy }=\frac{\mathrm{NXY}-\mathrm{XY}}{\sqrt{\left.\left.\mathrm{NX}^{2}-\mathrm{X}\right)^{2} \mathrm{NY}^{2}-\mathrm{Y}\right)^{2}}} . \\
& =\frac{(10 x 18500)-(435 x 405)}{\sqrt{\left[(10 x 20025)-(435)^{2}\right]\left[(1017225)(405)^{2}\right]}} \\
& =\frac{185000-176175}{\sqrt{[(200250-189225)][(172250-164025)]}} \\
& =\frac{8825}{\sqrt{11025 x 8225}} \\
& =\frac{8825}{\sqrt{90680625}} \\
& =\frac{8825}{9522.6} \\
& =0.927 \\
& \text { Df }=\mathrm{n}-1 \\
& =60-2 \\
& =58 \\
& \text { Where } \mathrm{n}=\text { number of respondents } \\
& =
\end{aligned}
$$

Critical value $=0.250$ 
Table 9. Pearson product moment correlation analysis of the relationship between high noise level and the health status of members of staff

\begin{tabular}{|c|c|c|c|c|}
\hline Variables & $\sum \mathrm{X}$ & \multicolumn{2}{|c|}{$\sum \mathrm{X} 2 \sum \mathrm{XY}$} & r-critical \\
\hline & & $\sum \mathrm{X}$ & $\sum \mathrm{Y} 2$ & \\
\hline High Noise level & $43520025 \mathrm{I} 8500$ & 0.765 & 0.250 & \\
\hline $\begin{array}{l}\text { Health Status of } \\
\text { Members of staff }\end{array}$ & 40517225 & & & \\
\hline
\end{tabular}

From table 9 above, the relationship between high noise level and the health status of members of staff yielded a Pearson product moment correlation co-efficient of 0.990 which was greater than the critical r-value of 0.250 at 0.05 level of significance with 58 degrees of freedom. This implies that the null hypothesis is rejected and an alternate hypothesis formulated which states that: there is a significant relationship between high noise level and the health status of members of staff.

\subsection{Summary of Findings}

The result of hypothesis one agrees with the psychoacoustic theory which shows that there is no significant variation in noise levels acquired at different temporal periods in Dangote flour mills. Also, hypothesis two reveals that there is a significant relationship between high noise level and the health status of members of staff. This finding is in line with [9] who assessed the effect of industrial noise pollution on the health of workers using 500 workers in a mining site in South Africa. The author found out that industrial noise pollution impairs task performance at work, increases errors, and decreases motivation. Reading attention, problem solving, and memory which are the basic components of cogntive development of workers are most strongly affected by industrial noise. The author further explained that two types of memory deficits have been identified under experimental conditions: recall of job content and recall of incidental details. Both are adversely influenced by industrial noise. Deficits in performance can lead to errors and accidents in the production sector, both of which have health and economic consequences. The result of the hypothesis is in correspondence with [10] who found out that industrial nosie pollution has a tremendous adverse effect on the cognitive development of workers as well as the people living near industrial estates. The author explained that cognitive and language development and reading achievement are diminished in noisy homes, even though the children's schools may be no noisier than average. Cognitive development is impaired when homes or schools are near sources of noise such as industrial, which affects learning, reading, problem solving, motivation, school performance and social and emotional development and therefore it is suggested that more attention needs to be paid to the effects of industrial noise on the ability of workers to learn new production methods and on the nature of the working environment. Moreover, there is a concern that high and continuous industrial noise may contribute to feelings of helplessness in children.

The result of the findings is also in agreement with [11] who stated that industrial noise produces negative after-effects on performance, particularly in industrial workers. It appears that the longer the exposure, the greater the effect on worker. Noisy areas have been found to have heightened sympathetic arousal indicated by increased levels of stress-related hormones and elevated resting blood pressure. These changes were larger in workers with lower production capacity.and further suggested that industrial noise should be reduced as much as possible. The result of this hypothesis also corresponds with that of [12] who found out that there is a significant relationship between industrial noise pollution and cadiovascular growth in humans that are exposed to it. The author further explained that temporary noise exposure produces readily reversible physiologic changes. However, noise exposure of sufficient intensity, duration, and unpredictability provokes changes that may not be so readily reversible. The studies that have been done on the effects of environmental noise have shown an association between noise exposure and subsequent cardiovascular disease. Even though the increased risk for noise-induced cardiovascular disease may be small, it assumes public health importance because both the number of people at risk and the noise to which they are exposed continue to increase. 
In summary, the results of the analysis showed that there is no significant variation in noise level at different temporal periods in Dangote flour mills and also there is a significant effect of high noise level on the health status of members of staff.

\section{Conclusion}

Based on the findings made in this research, it is concluded that there is no significant variation between noise level at different temporal periods in Dangote flour mills while there is a significant effect of high noise level on the health status of members of staff. This results were obtained because the data collected were analyzed using analysis of variance (ANOVA) and Pearson product moment correlation co-efficient statistical analysis. Sound level readings were taken at different temporal periods of morning, afternoon and evening. The statistical analysis showed that noise level in the industry have been found to increase throughout the morning period, afternoon and evening period.

\section{$5 \quad$ Recommendations}

Based on the findings and conclusion made in this study, the following recommendations were made;

1. The Federal and State Governments should make policies against certain level of noise pollution in industries in the state.

2. The Management of the company should ensure that the WHO regulation on industrial noise threshold is implemented and adhered to within the working environment.

3 . Workers and staff of the company should wear ear protective devices to reduce the effect of the noise on them.

4. The Government should enact laws against the importation of equipments that are over 15 years old.

5. The Management of the company should endeavour to get machines with the least noise level when making purchase of equipments for processing.

\section{References}

1. David, W. P(1995); Traffic noise and cardiovascular risk: the Caerphilly and Speedwell studies, second phase. Risk estimation, prevalence, and incidence of ischemic heart disease. Archieve of Environmental Health. 48(6): 406-413.

2. Obiefuna J. N, Bisong F. E, and Ettah E. B (2013) A GIS analysis of noise islands in Calabar Metropolis, Nigeria. Journal of Environment and Earth Science. (3)12

3. Jayant, R. and Stonecypher, L. (2010). Measuring Urban Noise Pollution on the Decibel Scale. Environmental Engineering Article On-line at http://www.brighthub.com/engineering/civil/articles/74443.aspx Browsed: August, 2010.

4. Passchier, C. P (2000). Effects of earplugs on catecholamine and cortisol excretion in noise-exposed textile workers. Ind Health. 1996;34(3):279-286.

5. Stanley, W. O (2001). Prospective study of noise exposure during pregnancy on birth weight. American Journal of Epidemiology 1996 Apr 15;143(8):792-796.

6. Nelson, L. I (1999);Personal and social variables as co-determinants of noise annoyance. Noise Health. Lagos; Open heaven publishing company.

7. Mager, D. M (1998); The Dormant Noise Control Act and Options to Abate Noise Pollution. Administrative Conference of the United States, 1991. Available at: http://www.nonoise.org/library/shapiro/shapiro.htm.

8. Charles, P. V(2005); Medical effects of aircraft noise: community cardiovascular survey. International Archieve of Occupational and Environmental Health. 1977 Nov 29;40(3):185-190.

9. Thony, A. S (2000);Environmental Protection Agency. Information on levels of environmental noise requisite to protect public health and welfare with an adequate margin of safety. EPA/ONAC 550/9-74-004. U.S. Environmental Protection Agency. Washington, DC. 1974. 
10.Set, F. T (1999); Industrial noise exposure, noise annoyance, and serum lipid levels in blue-collar workers--the CORDIS Study. Archieve of Environmental Health. 1999 Jul-Aug;52(4):292-298.

11.Fabara, Y. O (2006);Subjective work noise: a major risk factor in myocardial infarction. Texas; Soz Praventivmed publ.

12.Katty, E. F (2009); Tinnitus: A warning signal to teenagers attending discotheques? Noise Health.(2):1-2. 